\title{
Infarma - Ciências Farmacêuticas: identidade em todas as áreas das ciências que compõem a Farmácia em sua plenitude
}

\author{
Infarma - Pharmaceutical Sciences: in agreement with all \\ the sciences that constitute the Pharmacy plenitude
}

Anselmo Gomes de OLIVEIRA;

Dâmaris SILVEIRA

Editores-chefe

As Ciências Farmacêuticas correspondem a um largo espectro de disciplinas científicas essenciais para a descoberta e desenvolvimento de novos fármacos e ferramentas terapêuticas. São compostas de várias categorias, cada uma com diversas especialidades. Essa é a razão de ser tão difícil definir o que é um farmacêutico. E mais ainda, o que é um farmacêutico cientista. São tantas as áreas de atuação, tantas as áreas correlatas, que trabalhar com as Ciências Farmacêuticas significa poder escolher uma ou mais entre as centenas de possibilidades. $\mathrm{O}$ farmacêutico cientista tem tido um papel fundamental na descoberta e no desenvolvimento de fármacos e formas farmacêuticas inovadoras, contribuindo para a manutenção e a melhora da qualidade de vida de milhares de pessoas em todo o mundo.

No cenário brasileiro, Infarma - Ciências Farmacêuticas talvez seja o periódico que melhor reflete a amplitude das Ciências Farmacêuticas. Os artigos originais, publicados no ano que se encerra, transitaram entre temas tão diversos quanto equivalência farmacêutica, situações de uso de medicamentos, interações medicamentosas, determinação de atividades terapêuticas em plantas, morfologia vegetal, qualidade de alimentos, interferência de substâncias em análises bioquímicas, aspectos da qualidade de cosméticos, biossegurança, impacto de estágios no exterior, entre outros. As revisões incluíram tabagismo, plantas medicinais, biotecnologia, formas farmacêuticas, atenção farmacêutica, dentre outros, além das notas técnicas sobre armazenamento e degradação de medicamentos. A amplitude dos assuntos publicados ao longo do ano de 2018 também reflete o imenso campo das atividades do farmacêutico em sua atuação profissional.

Neste fascículo, que marca o encerramento do volume 30 de 2018, o leitor poderá transitar em grande variedade de assuntos relevantes das Ciências Farmacêuticas, os quais oferecem grande oportunidade de reflexão e ampliação de conhecimentos.

E ao finalizar mais um ano de atividades do periódico Infarma - Ciências Farmacêuticas e, com esse número, encerrar o volume 30 , gostaríamos de registrar a participação de autores estrangeiros e brasileiros, oriundos da maior parte das regiões de nosso país. Infarma - Ciências Farmacêuticas tem sido, muitas vezes, a porta de entrada de jovens pesquisadores que aqui publicam seus primeiros artigos. Também podem ser destacados autores experientes, que vislumbram, em Infarma - Ciências Farmacêuticas, não só um veículo de divulgação científica, mas muitas vezes uma fonte de consulta essencial para profissionais que atuam no mercado.

Agradecemos enfaticamente aos nossos assessores Ad Hoc, editores associados, e membros do corpo editorial pelo empenho e profissionalismo com o qual trabalharam em todos os artigos que compuseram as edições de Infarma - Ciências Farmacêuticas neste ano de 2018. 
Esse compromisso, voluntário e diário, é que permitiu que a publicação do volume 30 fosse concretizada. Aos nossos autores, grandes colaboradores, que contribuíram para uma amplitude significativa dos assuntos tratados dentro da área das Ciências Farmacêuticas, o nosso sincero reconhecimento. Seu papel é fundamental e permite a continuidade do periódico.
Para o próximo ano, esperamos que Infarma - Ciências Farmacêuticas continue ocupando um espaço importante na vida profissional do farmacêutico em nosso país. Esperamos, principalmente, o aumento do interesse dos profissionais em publicarem seus artigos em Infarma - Ciências Farmacêuticas, o periódico científico com identidade em todas as áreas das Ciências Farmacêuticas. 